\title{
The influence of birth weight and genetic factors on lipid levels: a study in adult twins
}

\author{
Chuluuntulga Tuya ${ }^{1}$, William J. Mutch ${ }^{2}$, Paul Haggarty ${ }^{3,4}$, Doris M. Campbell ${ }^{4}$, Alastair Cumming ${ }^{5}$, \\ Kevin Kelly ${ }^{6}$, Iain Broom ${ }^{2}$ and Geraldine McNeill ${ }^{7}$ * \\ ${ }^{1}$ Clinical Research Unit, NHS Grampian, Westburn House, Foresterhill, Aberdeen AB25 2XG, UK \\ ${ }^{2}$ Clinical Biochemistry Department, NHS Grampian, Foresterhill, Aberdeen, UK \\ ${ }^{3}$ Rowett Research Institute, Greenburn Road, Bucksburn, Aberdeen AB21 9SB, UK \\ ${ }^{4}$ Department of Obstetrics and Gynaecology, University of Aberdeen, Foresterhill, Aberdeen AB25 2ZD, UK \\ ${ }^{5}$ Department of Molecular and Cell Biology, University of Aberdeen, Foresterhill, Aberdeen AB25 2ZD, UK \\ ${ }^{6}$ Department of Medical Genetics, University of Aberdeen, Foresterhill, Aberdeen AB25 2ZD, UK \\ ${ }^{7}$ Department of Environmental and Occupational Medicine, University of Aberdeen, Foresterhill, Aberdeen AB25 2ZD, UK
}

(Received 14 February 2005 - Revised 14 July 2005 - Accepted 15 July 2005)

\begin{abstract}
Twins can be used to investigate the biological basis for observed associations between birth weight and later disease risk, as they experience in utero growth restriction compared with singletons, which can differ in magnitude within twin pairs despite partial or total genetic identity. In the present study, sixty monozygotic and seventy-one dizygotic same-sex twin pairs aged 19-50 years and eighty-nine singleton controls matched for age, gestational age, sex, maternal age and parity were recruited from an obstetric database. Associations between fasting lipid levels and birth weight were assessed by linear regression with adjustment for possible confounding factors. Twins were significantly lighter at birth but were not significantly different in adult height, weight or lipid levels from the singleton controls. There was a significant inverse association between birth weight and both total and LDL-cholesterol levels among singleton controls $(-0.53 \mathrm{mmol} / \mathrm{l}$ per kg $(95 \% \mathrm{CI}-0.97,-0.09), P=0.02$ and $-0.39 \mathrm{mmol} / \mathrm{l}$ per kg $(95 \% \mathrm{CI}-0.76,-0.02), P=0.04$, respectively), but there was no significant association between birth weight and lipid levels in either unpaired or within-pair analysis of twins. The results suggest that the in utero growth restriction and early catch-up growth experienced by twins does not increase the risk of an atherogenic lipid profile in adult life
\end{abstract}

Birth weight: Lipid levels: Twins

An association between birth weight and adult susceptibility to CVD, diabetes and hypertension has been reported by a number of groups in widely different cultural settings (Barker et al. 1993; Curhan et al. 1996; Stein et al. 1996; Rich-Edwards et al. 1997, 1999; Forsen et al. 1999; Huxley et al. 2000; Burke et al. 2004). The 'fetal origins' hypothesis proposes that this association is causal as a result of 'predictive adaptive responses' made by the fetus to undernutrition in utero, which persist into adulthood and increase susceptibility to the metabolic effects of overnutrition in later life (Barker, 1995, 1998, 1999; Gluckman \& Hanson, 2004). Although in man the evidence for a close relationship between birth weight and maternal diet is limited, intervention studies in animals provide support for the possibility that maternal nutrient intake may influence both size at birth and later disease risk (McMillen \& Robinson, 2005).

Although much of the literature on the fetal origins hypothesis has focused on hypertension and insulin resistance, increased plasma lipid levels are also a major independent risk factor for CVD (Poulter, 2003). A systematic review of thirty-two studies in singletons found a weak inverse association between birth weight and total cholesterol (Owen et al. 2003), but a more recent review of seventynine studies concluded that impaired fetal growth does not have effects on blood cholesterol levels that would have a material impact on vascular disease risk (Huxley et al. 2004). Another systematic review of thirty-nine studies, which included other lipid measures, also concluded that there was no consistent relationship between size at birth and blood lipid concentrations in later life, with the possible exception of a negative association between birth weight and triacylglycerol concentration (Laurèn et al. 2003). Thus, there remains considerable uncertainty as to the strength of the relationship with birth weight and, if the relationship does exist, whether fetal undernutrition is the underlying mechanism. One alternative interpretation is that the same genes that predispose to adult disease also result in low birth weight (Hattersley \& Tooke, 1999; Eriksson et al. 2002) as there is evidence that genetic factors contribute to the variation in birth weight (Magnus, 1984; Magnus et al. 1997) and lipid levels (Boekholdt et al. 2004). Twin studies provide an opportunity to separate the influence of the early environment and the influence of genetic factors, since twins experience in utero growth restriction and in addition experience 
postnatal catch-up growth, which has been identified as an additional risk factor for later CVD in singletons (Eriksson et al. 1999). Furthermore, the importance of genetic factors in explaining an association between birth weight and disease risk can be assessed by comparing the magnitude of the effect in dizygotic $v$. monozygotic twin pairs. A recent study of adolescent twins using this approach found significant correlations in dizygotic but not monozygotic pairs, which suggested that genetic factors contribute to the relationship between birth weight and later plasma lipid concentrations (Ijzerman et al. 2001). However, another study found that in monozygotic twin pairs the lower-birth-weight twins tended to have higher triacylglycerol and lower HDL-cholesterol levels than the higher-weight twins, suggesting that non-genetic factors play a role in this relationship (Bo et al. 2001).

We have previously reported the results of a study of adult twins and singleton controls designed to investigate whether genetic factors contribute to association between size at birth and blood pressure, insulin resistance and fibrinogen levels in adult life (McNeill et al. 2003; Tuya et al. 2003, 2005). In the present paper we explore the relationship between birth weight and fasting lipid concentrations using the same study design. We also report the total genetic contribution to variation in the lipid levels based on the classical twin study design.

\section{Methods}

\section{Subjects}

The Aberdeen Maternity and Neonatal Databank is a computerised register of all births that have occurred at Aberdeen Maternity Hospital in Aberdeen, Scotland, since 1949. It contains detailed obstetric information including gestation and birth weight recorded at delivery. Between 1949 and 1980 there were 792 same-sex-twin live births at Aberdeen Maternity Hospital. Of these, 465 twin pairs $(59 \%)$ in which one or both twins were living in the Grampian region were traced via the local Community Health Index (a database of all individuals registered with the National Health Service) in 1999. To identify singleton controls, each twin delivery was matched with up to four live singleton deliveries of the same sex, gestational age ( \pm 1 week), maternal age ( \pm 5 years) and parity $(0,1$ or $\geq 2)$, and year of birth ( \pm 1 year). Of these, 442 individuals living in Grampian were traced through the Community Health Index. In fifteen twin pairs, one or both twins were excluded by the family doctor for medical reasons, as was one singleton. All others were sent a letter of information about the study and 131 twin pairs $(32 \%)$ and ninety-three singletons $(21 \%)$ agreed to participate and attended for measurements. Acute and/or chronic illness was excluded using a standardised questionnaire. Four singletons were later excluded from analysis as a result of errors discovered in the matching of singleton and twin deliveries. The effect of oral contraceptives on lipid levels was assessed by linear regression with adjustment for oral contraceptive use. None of the subjects used any other medication that may affect serum lipid profile. Thus, 131 twin pairs and eighty-nine singleton controls were eligible for analysis.

\section{Measurements and questionnaire}

Measurements were made of height, weight and waist circumference in each subject. BMI was calculated $\left(\mathrm{kg} / \mathrm{m}^{2}\right)$. Body fat was measured by bioelectrical impedance analysis using the Bodystat ${ }^{\circledR} 1500$ (Bodystat Ltd, Isle of Man). Medical details, smoking and occupation were obtained by a questionnaire based on that used in the Scottish MONICA study (Smith et al. 1989). The physical activity questions were a modified version of those used for the Framingham Physical Activity Index (Kannel \& Sorlie, 1979). Diet was assessed using version 6.31 of the Scottish Collaborative Group semi-quantitative food-frequency questionnaire (Masson et al. 2003).

\section{Clinical and laboratory investigations}

An overnight fasting venous blood sample was taken for measurements of cholesterol, triacylglycerols and apolipoproteins. Total cholesterol, HDL-cholesterol and triacylglycerols were measured on the Bayer ADVIA $1650{ }^{\circledR}$ (Bayer Healthcare, Newbury, UK) and LDL-cholesterol was calculated using the Friedewald equation (Friedewald et al. 1972). Apo A1 and apo B were measured by in vitro diagnostic reagents $\mathrm{N}$ Antisera using the Behring Rate Nephelometer (Dade Behring Ltd, Milton Keynes, $\mathrm{UK})$. The interassay CV was $<2 \%$ for total cholesterol and triacylglycerols. For all other assays it was $<5 \%$. The laboratory references for all analytes were in the relevant United Kingdom National Quality Assurance Scheme.

Birth weight, gestational age, maternal age and parity for both twins and controls were obtained from obstetric records in the Aberdeen Maternity Neonatal Databank. Self-reported birth order was used to link the relevant obstetric information from the Aberdeen Maternity Neonatal Databank to individual twins from each pair. Zygosity was determined by DNA fingerprinting using a venous blood sample. Ten short tandem repeats were analysed using the AmpFLSTR Profiler on the ABI 310 genetic analyzer (Applied Biosystems, Foster City, CA, USA).

The study protocol was approved by the Grampian Research Ethics Committee, and all subjects gave informed written consent to participate.

\section{Statistical analysis}

The contribution of genetic and shared and non-shared environmental effects for the total variation in lipid risk factors was assessed using an ACE twin model using the Mx program (Neale et al. 2004) for twin data (Purcell, 2000). This partitions the total variance in a trait into Additive genetic variance and Common (shared) and unique Environmental effects. The variance-covariance matrix for each of the parameters was calculated for the monozygotic and dizygotic twins following adjustment by multiple regression. In the basic model only sex and age were adjusted for, while in the fully adjusted model the data were adjusted for sex, age, percentage body fat, dietary polyunsaturated:saturated fatty acid ratio, dietary percentage energy as fat, physical activity level, and the use of oral contraceptives.

Differences in birth weight, anthropometric variables and lipid measurements between twins and singleton controls were assessed by Mann-Whitney tests. The relationships between birth weight and adult lipid levels were assessed by linear regression with adjustment for current age, sex, gestational age, percentage body fat, physical activity, oral contraceptive use, percentage energy from fat and polyunsaturated:saturated fatty acid ratio. Regression coefficients for the relationships between lipid levels and birth weight in the unpaired analysis in twins were 
estimated using generalised estimating equations with an exchangeable correlation structure to model the correlated nature of the sample.

In addition, linear regression analysis was used to assess the association between within-pair differences in birth weight and differences in lipid levels before and after adjustment for differences in confounding variables. In within-pair analysis the differences between first- and second-born twins were used rather than the differences between heavier and lighter twins at birth, as the range of birth-weight differences is wider with both positive and negative values in the former than the latter, which improves the estimation of the regression coefficient (Bring \& Wernroth, 1999). Difference in oral contraceptive use was assessed by coding twins on oral contraceptive, not on oral contraceptive but co-twins on oral contraceptive, and not on oral contraceptive, as 2, 1, and 0 respectively, and subtracting the code for the second-born twin from that for the first-born twin. These analyses were carried out using SPSS version 11 (SPSS Inc., Chicago, IL, USA) and STATA version 7.0 (StataCorp LP, College Station, TX, USA).

\section{Results}

There were no significant differences in current age, birth weight, gestational age or maternal parity between participants and nonparticipants, although the percentage of female twins who participated was higher than the percentage of male twins (Table 1).

The birth weights, adult characteristics and lipid profile of the participating twins and singleton controls are shown in Tables 2 and 3. Male participants were slightly older than female participants in both twins $(P<0.001)$ and singleton controls $(P<0.05)$, which may reflect difficulties involved in tracing older women as a result of changes of names on marriage. As expected the singleton controls (both males and females) had a significantly higher birth weight than the twins $(P<0.001$ for both), even though there was no difference in gestational age. However, there were no differences in plasma lipid concentrations, adult height and weight, or BMI between twins and singletons in either males or females.

Among the twins, birth weight and gestational age were not significantly different between monozygotic and dizygotic twins (data not shown), but current age was significantly higher in dizygotic twins than in monozygotic twins among both males and females $(P=0.05$ and $P=0.04$, respectively). Adult weight, BMI, percentage body fat and triacylglycerol levels were also significantly higher in dizygotic twins than in monozygotic twins among the males $(P=0.02, \quad P=0.01, \quad P=0.005$ and $P=0 \cdot 006$, respectively).

Table 4 shows the results of the ACE analysis, which indicate that $40-50 \%$ of the variance in HDL-cholesterol and apo A1 was genetically determined. In the case of apo B about $60 \%$ of the variation was genetically determined, but this effect appeared to be operating largely via a genetic influence on the percentage body fat as adjustment for this factor in particular was largely responsible for the removal of the genetic effect in the fully adjusted model. The model also calculated a genetic influence on LDL-cholesterol of the same order of magnitude but this was not significant because of the high variance in this parameter in the dizygotic twins in particular. As with apo B, even this non-significant effect was removed after full adjustment, again largely due to the effect of body fat.

Although there was a wide range of within-pair differences in birth weight, adult height, BMI and lipid concentrations in all variables, for example, up to $1.8 \mathrm{~kg}$ in birth weight and up to $3.8 \mathrm{mmol} / \mathrm{l}$ in total cholesterol concentrations, the range of within-pair differences was similar in monozygotic and dizygotic twin pairs (data not shown). Table 5 shows the regression coefficients for the association between birth weight and lipid levels in singletons and twins. There was a significant negative relationship between within-pair

Table 1. Obstetric data of participating and non-participating twin pairs and singleton controls (Mean values with their standard errors)

\begin{tabular}{|c|c|c|c|c|c|c|c|c|c|c|}
\hline & \multicolumn{2}{|c|}{$\begin{array}{l}\text { Participants } \\
\text { (131 twin pairs) }\end{array}$} & \multicolumn{2}{|c|}{$\begin{array}{l}\text { Non-participants } \\
\text { (663 twin pairs) }\end{array}$} & \multirow[b]{2}{*}{$P$} & \multicolumn{2}{|c|}{$\begin{array}{l}\text { Participants } \\
\text { (n 89) }\end{array}$} & \multicolumn{2}{|c|}{$\begin{array}{l}\text { Non-participants } \\
\text { (n 478) }\end{array}$} & \multirow[b]{2}{*}{$P$} \\
\hline & Mean & SEM & Mean & SEM & & Mean & SEM & Mean & SEM & \\
\hline Age (years) & $33 \cdot 2$ & 0.80 & $34 \cdot 1$ & 0.38 & NS & $33 \cdot 7$ & 1.04 & $31 \cdot 3$ & 0.42 & NS \\
\hline First-born & 2582 & $47 \cdot 73$ & 2498 & $20 \cdot 11$ & NS & 2942 & 62.94 & 2933 & 30.46 & NS \\
\hline Second-born & 2394 & 44.02 & 2351 & $20 \cdot 34$ & NS & & & & & \\
\hline \multicolumn{11}{|l|}{ Sex } \\
\hline \multicolumn{11}{|l|}{ Male pairs } \\
\hline$n$ & \multicolumn{2}{|c|}{53} & \multicolumn{2}{|c|}{352} & NS & \multicolumn{2}{|c|}{47} & \multicolumn{2}{|c|}{261} & NS \\
\hline$\%$ & \multicolumn{2}{|c|}{$40 \cdot 5$} & \multicolumn{2}{|c|}{$53 \cdot 1$} & & \multicolumn{2}{|c|}{$52 \cdot 8$} & \multicolumn{2}{|c|}{$54 \cdot 6$} & \\
\hline \multicolumn{11}{|l|}{ Primiparous } \\
\hline$n$ & \multicolumn{2}{|c|}{51} & \multicolumn{2}{|c|}{229} & NS & \multicolumn{2}{|c|}{31} & & & NS \\
\hline$\%$ & & & & & & & & & & \\
\hline Multiparous & & & & & & & & & & \\
\hline$n$ & & & & & NS & & & & & NS \\
\hline$\%$ & & & & & & & & & & \\
\hline
\end{tabular}


Table 2. Birth weights and adult characteristics of twins and singleton controls

(Mean values and standard deviations)

\begin{tabular}{|c|c|c|c|c|c|c|c|c|}
\hline & \multicolumn{4}{|c|}{ Males } & \multicolumn{4}{|c|}{ Females } \\
\hline & \multicolumn{2}{|c|}{ Twins (n 106) } & \multicolumn{2}{|c|}{ Singletons ( $n$ 46) } & \multicolumn{2}{|c|}{ Twins ( $n$ 156) } & \multicolumn{2}{|c|}{ Singletons (n 43) } \\
\hline & Mean & SD & Mean & SD & Mean & SD & Mean & SD \\
\hline Birth weight $(\mathrm{g})$ & $2606 \cdot 2$ & 534.9 & $2955 \cdot 6^{\star}$ & $486 \cdot 8$ & 2398.9 & $526 \cdot 0$ & $2927 \cdot 3^{\star}$ & $696 \cdot 0$ \\
\hline Gestational age (weeks) & 37.2 & $2 \cdot 8$ & 36.7 & $2 \cdot 3$ & 37.3 & 2.7 & 37.2 & 2.7 \\
\hline Current age (years) & $36 \cdot 2$ & $8 \cdot 7$ & $35 \cdot 7$ & $9 \cdot 8$ & 30.5 & $8 \cdot 7$ & $31 \cdot 1$ & $9 \cdot 41$ \\
\hline Adult height $(\mathrm{cm})$ & $177 \cdot 2$ & 6.9 & $176 \cdot 0$ & $5 \cdot 8$ & $162 \cdot 5$ & $6 \cdot 7$ & $162 \cdot 0$ & $6 \cdot 6$ \\
\hline Adult weight (kg) & $80 \cdot 0$ & $12 \cdot 7$ & 80.6 & 13.7 & 63.8 & $12 \cdot 9$ & $60 \cdot 1$ & 8.8 \\
\hline BMI $\left(\mathrm{kg} / \mathrm{m}^{2}\right)$ & $25 \cdot 5$ & 3.7 & $26 \cdot 0$ & 3.9 & $24 \cdot 2$ & 4.8 & $22 \cdot 9$ & $3 \cdot 0$ \\
\hline Body fat (\%) & $20 \cdot 0$ & $5 \cdot 8$ & $21 \cdot 0$ & $5 \cdot 7$ & 29.8 & $8 \cdot 2$ & $28 \cdot 4$ & $6 \cdot 7$ \\
\hline
\end{tabular}

*Mean value was significantly different from that for twins of the same sex $(P<0.001)$.

differences in birth weight and differences in both total and HDLcholesterol in monozygotic twins, in the unadjusted analyses $(-0.29 \mathrm{mmol} / 1$ per $\mathrm{kg}(95 \% \mathrm{CI}-0.49,-0.09), P=0.004$ and $-0.11 \mathrm{mmol} / \mathrm{l}$ per $\mathrm{kg}(95 \% \mathrm{CI} 0 \cdot 22,0.00), P=0.04$, respectively), but this was not seen in the adjusted models. In the analysis of all twins, both unadjusted and adjusted regression coefficients were small and were not statistically significant. However, in singleton controls, there were significant inverse associations between birth weight and both total and LDL-cholesterol concentrations in the adjusted models.

\section{Discussion}

Despite the smaller numbers of singleton controls in the present study, we found a significant inverse association between birth weight and lipid levels in the singleton controls. This was in line with the inverse associations between birth weight and diastolic blood pressure, glycated $\mathrm{Hb}\left(\mathrm{HbA}_{1} \mathrm{C}\right)$ and clottable fibrinogen observed in these subjects (McNeill et al. 2003; Tuya et al. 2003, 2005). The possibility that genetic factors might contribute to this association was supported by the observation that in the twins the ACE analysis confirmed the importance of genetic factors in determining lipid levels. However, in the unpaired analysis in twins we found no association between birth weight and lipid levels. In addition there was no difference in lipid levels between the twins and singleton controls despite the lower birth weight and postnatal catch-up growth in the twins. Taken together, these results suggest that the type of intra-uterine growth restriction and postnatal catch-up growth seen in twins does not have an adverse effect on lipid levels in later life. Phillips et al. (2001) suggested that small size at birth in twins may not have the same origin as small size in singletons, which could be due to the fact that growth restriction in twins only occurs from about 32 weeks (Loos et al. 2005). Gluckman \& Hanson (2004) also raised the possibility that maternal constraint on fetal growth as a result of increased fetal demand for nutrients, as seen in multiple pregnancies, could have different mechanisms from that due to decreased maternal supply. Another factor that may influence birth weight in monozygotic twins is twin-twin transfusion syndrome, which can occur in two-thirds of monozygotic twin pairs that are monochorionic, and may result in birth-weight discordance and blood lipid level differences through mechanisms not experienced by singletons (Lopiore $e t$ al. 2003). It was not possible to explore this aspect in the present study, as chorionicity information was only recorded in twentynine of the sixty monozygotic pairs. For postnatal growth it is also possible that the pattern of catch-up growth seen in twins, which mostly occurs in the first 2 years of life (Keet et al. 1986), may have different effects to accelerated growth or overnutrition in later childhood. Another way in which twins could differ from singletons is in infant feeding, as twins may be breast-fed less commonly or for shorter periods than singletons; breast-feeding in the Caerphilly study was found to be associated with CHD mortality and incidence (Martin et al. 2005). However, the subjects of the present study were born at a time when infant formulae were more similar in composition to breast milk; in addition, twins within a pair are likely to have been fed by the same method so the within-pair analyses are unlikely to be influenced by this issue.

Table 3. Fasting plasma lipid concentrations in twins and singleton controls (Mean values and standard deviations)

\begin{tabular}{|c|c|c|c|c|c|c|c|c|}
\hline & \multicolumn{4}{|c|}{ Males } & \multicolumn{4}{|c|}{ Females } \\
\hline & \multicolumn{2}{|c|}{ Twins ( $n$ 106) } & \multicolumn{2}{|c|}{ Singletons ( $n$ 46) } & \multicolumn{2}{|c|}{ Twins ( $n$ 156) } & \multicolumn{2}{|c|}{ Singletons ( $n$ 43) } \\
\hline & Mean & SD & Mean & SD & Mean & SD & Mean & SD \\
\hline Total cholesterol $(\mathrm{mmol} / \mathrm{l})$ & 4.95 & 1.03 & $5 \cdot 18$ & 0.93 & 4.73 & 1.04 & 4.71 & 1.04 \\
\hline HDL-cholesterol (mmol/l) & 1.40 & 0.33 & 1.44 & 0.34 & $1 \cdot 70$ & 0.38 & $1 \cdot 70$ & 0.35 \\
\hline LDL-cholesterol (mmol/l) & 3.01 & 0.87 & 3.18 & 0.79 & $2 \cdot 63$ & 0.88 & $2 \cdot 60$ & 0.87 \\
\hline Triacylglycerols (mmol/l) & $1 \cdot 19$ & 0.78 & $1 \cdot 23$ & 0.58 & 0.89 & 0.52 & 0.90 & 0.38 \\
\hline Apo A1 $(g / l)$ & 1.35 & 0.23 & 1.40 & 0.23 & 1.46 & 0.25 & 1.51 & 0.21 \\
\hline Apo B (g/l) & $1 \cdot 13$ & 0.32 & $1 \cdot 16$ & 0.33 & 0.96 & 0.32 & 0.97 & 0.31 \\
\hline
\end{tabular}



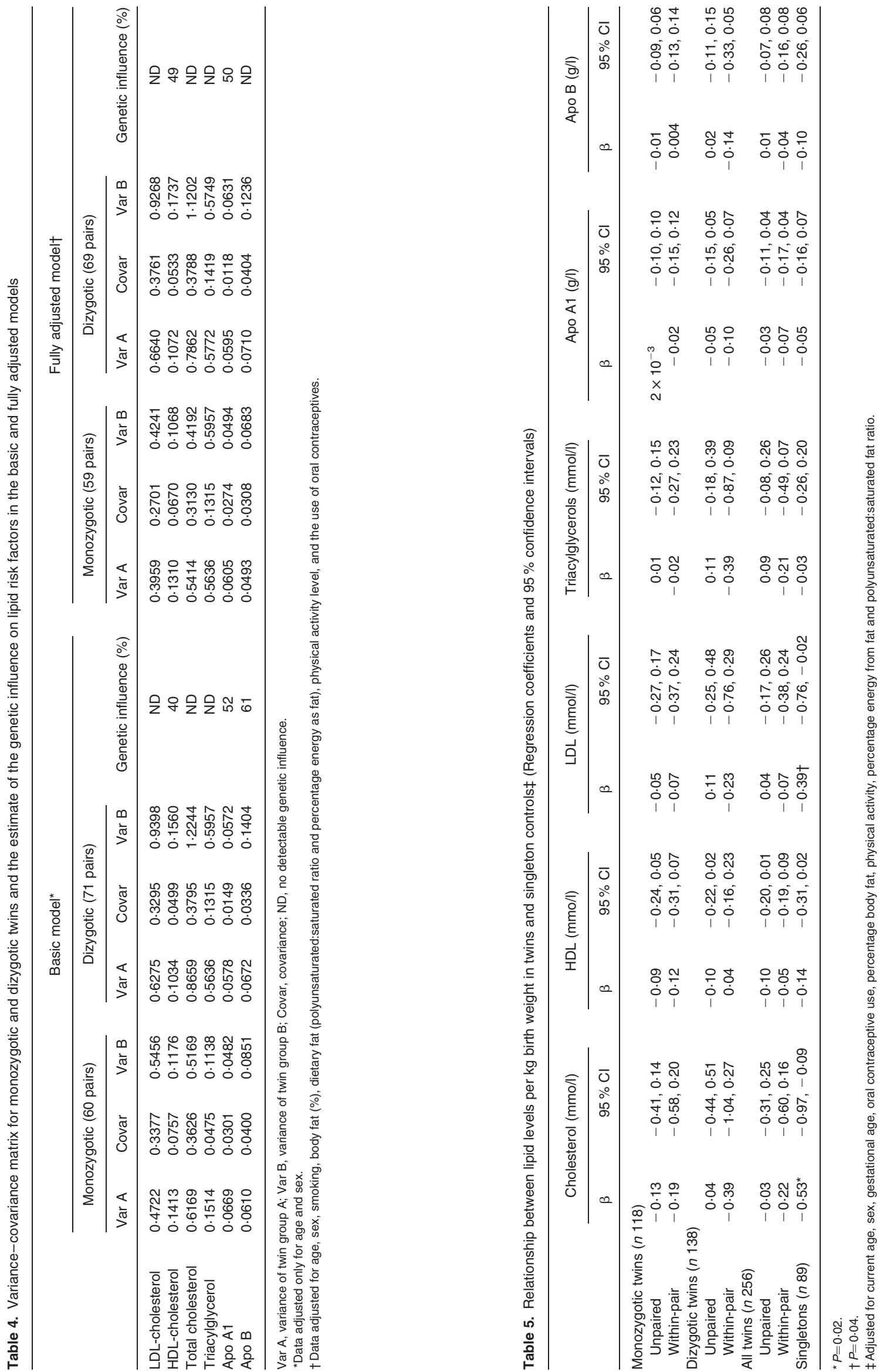
As there was no association between birth weight and lipid levels in the unpaired twins it was not surprising that there was no evidence for an attenuation of the effect in the within-pair analysis in monozygotic $v$. dizygotic pairs. This is in contrast to a recent study of adolescent twins (sixty-one monozygotic and fifty-three dizygotic pairs), which found that low birth weight was associated with high total and LDL-cholesterol in dizygotic twin pairs, but with low total and LDL-cholesterol in monozygotic twin pairs, suggesting a genetic effect on the association (Ijzerman et al. 2001), although the unpaired analysis in twins was not presented. It is not clear why the results of the two studies differ; the major difference is that in the present study the subjects were older, but the influence of birth weight on cardiovascular risk factors might be expected to increase rather than decrease with age. In the study of Ijzerman et al. (2001), birth weight was ascertained from the mothers by questionnaire and zygosity was determined by similarity questions, while in our subjects birth weight was obtained from medical records and zygosity was determined through sequential analysis based on DNA fingerprints, so it is unlikely that errors in zygosity or birth weight could account for the lack of effect in the present study.

In summary we found evidence for an inverse association between birth weight and total and LDL-cholesterol in singletons and for a genetic influence on lipid levels in the twins. No association between birth weight and lipid levels was seen in unpaired twins, and there was no significant difference in adult lipid levels between the twins and the singleton controls. Differences in growth patterns in prenatal and early postnatal life between twins and singletons may help to identify the nature and timing of early life influences on adult disease risk.

\section{Acknowledgements}

The study was funded by the Scottish Office (Chief Scientist Office), contract no. K/MRS/50/C2706. We thank Freda Ness and Lindsey Masson for assistance with the data collection and Graham Horgan of BioSS for his advice on the estimation of the genetic contribution to the variance.

\section{References}

Barker DJ, Hales CN, Fall CH, Osmond C, Phipps K \& Clark PM (1993) Type 2 (non-insulin-dependent) diabetes mellitus, hypertension and hyperlipidaemia (syndrome X): relation to reduced fetal growth. Diabetologia 36, 62-67.

Barker DJP (1995) Fetal origins of coronary heart disease. BMJ 311, $171-174$.

Barker DJP (1998) Mothers, Babies and Health in Later Life. Edinburgh: Churchill Livingstone.

Barker DJP (1999) Fetal origins of cardiovascular disease. Ann Med 31, 3-6.

Bo S, Cavallo-Perin P, Ciccone G, Scaglione L \& Pagano G (2001) The metabolic syndrome in twins: a consequence of low birth weight or of being a twin? Exp Clin Endocrinol Diabetes 109, 135-140.

Boekholdt SM, Kuivenhoven JA, Hovingh GK, Jukema JW, Kastelein JJ \& van Tol A (2004) CETP gene variation: relation to lipid parameters and cardiovascular risk. Review. Curr Opin Lipidol 15, 393-398.

Bring J \& Wernroth L (1999) Inefficient analysis of twin data: is there an association between diabetes and birth weight? Diabetologia 42, $898-899$.

Burke JP, Forsgren J, Palumbo PJ, Bailey KR, Desai J, Devlin H \& Leibson CL (2004) Association of birth weight and type 2 diabetes in Rochester, Minnesota. Diabetes Care 27, 2512-2513.
Curhan GC, Chertow GM, Willett WC, Spiegelman D, Colditz GA, Manson JE, Speizer FE \& Stampfer MJ (1996) Birth weight and adult hypertension and obesity in women. Circulation 94, 1310-1315.

Eriksson JG, Forsen T, Tuomilehto J, Winter PD, Osmond C \& Barker DJ (1999) Catch-up growth in childhood and death from coronary heart disease: longitudinal study. BMJ 318, 427-431.

Eriksson JG, Lindi V, Uusitupa M, Forsen TJ, Laakso M, Osmond C \& Barker DJ (2002) The effects of the Pro12Ala polymorphism of the peroxisome proliferator-activated receptor-gamma2 gene on insulin sensitivity and insulin metabolism interact with size at birth. Diabetes $\mathbf{5 1}$, 2321-2324.

Forsen T, Eriksson JG, Tuomilehto J, Osmond C \& Barker DJP (1999) Growth in utero and during childhood among women who develop coronary heart disease: longitudinal study. BMJ 319, 1403-1407.

Friedewald WT, Levy RI \& Fredrickson DS (1972) Estimation of the concentration of low-density lipoprotein cholesterol in plasma, without use of the preparative ultracentrifuge. Clin Chem 18, 499-502.

Gluckman PD \& Hanson MA (2004) Maternal constraint of fetal growth and its consequences. Review. Semin Fetal Neonatal Med 9, 419-425.

Hattersley AT \& Tooke JE (1999) The fetal insulin hypothesis: an alternative explanation of the association of low birthweight with diabetes and vascular disease. Lancet 353, 1789-1792.

Huxley R, Owen CG, Whincup PH, Cook DG, Colman S \& Collins R (2004) Birth weight and subsequent cholesterol levels: exploration of the "fetal origins" hypothesis. JAMA 292, 2755-2764.

Huxley RR, Shiell AW \& Law CM (2000) The role of size at birth and postnatal catch-up growth in determining systolic blood pressure: a systematic review of the literature. J Hypertens 18, 815-831.

Ijzerman RG, Stehouwer CD, van Weissenbruch MM, De Geus EJ \& Boomsma DI (2001) Evidence for genetic factors explaining the association between birth weight and low-density lipoprotein cholesterol and possible intrauterine factors influencing the association between birth weight and high-density lipoprotein cholesterol: analysis in twins. $J$ Clin Endocrinol Metab 86, 5479-5484.

Kannel WB \& Sorlie P (1979) Some health benefits of physical activity: the Framingham Heart Study. Arch Intern Med 139, 857-861.

Keet MP, Jaroszewicz AM \& Lombard CJ (1986) Follow-up study of physical growth of monozygous twins with discordant within-pair birth weights. Pediatrics 77, 336-344.

Laurèn L, Jarvelin MR, Elliott P, et al. (2003) Relationship between birthweight and blood lipid concentrations in later life: evidence from the existing literature. Int J Epidemiol 32, 862-876.

Loos RJ, Derom C, Derom R \& Vlietinck R (2005) Determinants of birthweight and intrauterine growth in liveborn twins. Paediatr Perinat Epidemiol 19, 15-22.

Lopiore E, Nagel HT, Vandenbussche FR \& Walther FJ (2003) Long-term neurodevelopmental outcome in twin-to-twin transfusion syndrome. Am J Obstet Gynecol 189, 1314-1319.

McMillen IC \& Robinson JS (2005) Developmental origins of the metabolic syndrome: prediction, plasticity, and programming. Review. Physiol Rev 85, 571-633.

McNeill G, Tuya C, Campbell DM, Haggarty P, Smith WC, Masson LF, Cumming A, Broom I \& Haites N (2003) Blood pressure in relation to birth weight in twins and singleton controls matched for gestational age. Am J Epidemiol 158, 150-155.

Magnus P (1984) Causes of variation in birth weight: a study of offspring of twins. Clin Genet 25, 15-24.

Magnus P, Bakketeig LS \& Hoffman H (1997) Birth weight of relatives by maternal tendency to repeat small-for-gestational-age (SGA) births in successive pregnancies. Acta Obstet Gynecol Scand 165, Suppl., $35-38$.

Martin RM, Ben-Shlomo Y, Gunnell D, Elwood P, Yarnell JW \& Davey Smith G (2005) Breast feeding and cardiovascular disease risk factors, incidence, and mortality: the Caerphilly study. J Epidemiol Community Health 59, 121-129.

Masson LF, McNeill G, Tomany JO, Simpson JA, Peace HS, Wei L, Grubb DA \& Bolton-Smith C (2003) Statistical approaches for asses- 
sing the relative validity of a food frequency questionnaire: use of correlation coefficients and the kappa statistic. Public Health Nutr 6, 313-321.

Neale MC, Boker SM, Xie G \& Maes HH (2004) Mx: Statistical Modeling. 6th edition. Richmond, VA: Virginia Commonwealth University, Department of Psychiatry.

Owen CG, Whincup PH, Odoki K, Gilg JA \& Cook DG (2003) Birth weight and blood cholesterol level: a study in adolescents and systematic review. Pediatrics 111, 1081-1089.

Phillips DI, Davies MJ \& Robinson JS (2001) Fetal growth and the fetal origins hypothesis in twins - problems and perspectives. Twin Res $\mathbf{4}$, 327-331.

Poulter N (2003) Global risk of cardiovascular disease. Heart 89, Suppl. 2, ii2-ii5, ii35-ii37.

Purcell S (2000) Behavioural Genetic Interactive Modules. http://statgen. iop.kcl.ac.uk/bgim/index2.html

Rich-Edwards JW, Colditz GA, Stampfer MJ, Willett WC, Gillman MW, Hennekens CH, Speizer FE \& Manson JE (1999) Birthweight and the risk for type 2 diabetes mellitus in adult women. Ann Intern Med 130, 278-284.

Rich-Edwards JW, Stampfer MJ, Manson JE, Rosner B, Hankinson SE, Colditz GA, Willett WC \& Hennekens CH (1997) Birth weight and risk of cardiovascular disease in a cohort of women followed up since 1976. BMJ 315, 396-400.

Smith WCS, Tunstall-Pedoe H, Crombie IK \& Tavendale R (1989) Concomitants of excess coronary deaths - major risk factor and lifestyle findings from 10,359 men and women in Scottish Heart Health Study. Scot Med J 34, 550-555.

Stein CE, Fall CH, Kumaran K, Osmond C, Cox V \& Barker DJ (1996) Fetal growth and coronary heart disease in south India. Lancet 348, 1269-1273.

Tuya C, Mutch W, Broom J, Campbell DM \& McNeill G (2003) Size at birth, fasting glucose and insulin levels and insulin resistance in adult twins. Twin Res 6, 302-306.

Tuya C, Mutch WJ, Broom I \& McNeill G (2005) The effect of birth weight on clottable and intact fibrinogen levels: a twin study. J Thromb Haemost 3, 1143-1148. 